\title{
Concurrent Double Primary Tumours: Papillary Thyroid Carcinoma and Cervical Epithelioid Angiosarcoma
}

\author{
Eşzamanlı Çift Birincil Tümörler: Papiller Tiroid Karsinomu \\ ve Servikal Epiteloid Anjiyosarkom
}

\section{Sai Guan Lum $\odot$, Nurhamizah Mahmud $\odot$, Nurismah Isa $\odot$, Marina Mat Baki $\odot$}

Ethics Committee Approval: Not Applicable.

Conflict of interest: The authors declare that they have no conflict of interest.

Funding: None.

Informed Consent: Informed consent was taken.
Cite as: Lum SG, Mahmud N, Isa N, Mat Baki M. Concurrent double primary tumours: papillary thyroid carcinoma and cervical epithelioid angiosarcoma. Medeni Med J. 2020:35:349-55.

\begin{abstract}
Angiosarcoma is one of the rarest types of malignant vascular tumours that involved the head and neck region. It predominantly affects the scalp and superficial soft tissues. Angiosarcoma arising from the deep cervical soft tissue is extremely rare. There is a limited literature on neck angiosarcoma that occurred simultaneously with papillary thyroid carcinoma. We report a rare case of concurrent papillary thyroid carcinoma and cervical epithelioid angiosarcoma, and postoperative rapid progression of residual angiosarcoma that mimicked a neck haematoma. The diagnostic challenge and possible etiologies have been discussed here.
\end{abstract}

Keywords: Angiosarcoma, multiple primary neoplasms, papillary thyroid carcinoma, synchronous neoplasms, thyroid neoplasms, thyroid cancer

Öz

Anjiyosarkom baş ve boyun bölgesindeki kötü huylu vasküler tümörlerin en nadir görülen türlerinden biridir. Ağırlıklı şekilde kafa derisini ve yüzeysel yumuşak dokuları etkilemektedir. Derin servikal yumuşak dokudan kaynaklanan anjiyosarkom görülmesi oldukça nadirdir. Papiller tiroid karsinomu ile eşzamanlı olarak ortaya çıkan boyun anjiyosarkomuna ilişkin sınırı bir alanyazın vardır. Nadir bir eşzamanlı papiller tiroid karsinomu ile servikal epiteloid anjiyosarkomu ve boyun hematomunu taklit eden rezidüel anjiyosarkomun ameliyat sonrası hızlı ilerlemesini bildirmekteyiz. Teşhis zorluğu ve olası etiyolojiler burada tartışılmıştır.

Anahtar kelimeler: Anjiyosarkom, çoklu birincil neoplazmalar, papiller tiroid karsinomu, senkron neoplazmalar, tiroid neoplazileri, tiroid kanseri
Received: 14 November 2020

Accepted: 5 December 2020

Online First: 25 September 2020

Corresponding Author:

M. Mat Baki

ORCID: 0000-0002-9282-874X

Universiti Kebangsaan Malaysia Medical Centre, Hospital Canselor Tuanku Muhriz, Department of Otorhinolaryngology, Head and Neck Surgery, Kuala Lumpur, Malaysia

marinamatbaki@ppukm.ukm.edu.my

N. Mahmud

ORCID: 0000-0001-6462-1728

S.G. Lum

ORCID: 0000-0002-7397-9315

Universiti Kebangsaan

Malaysia Medical Centre,

Hospital Canselor Tuanku Muhriz, Department of Otorhinolaryngology, Head and Neck Surgery, Kuala Lumpur, Malaysia

N. Isa

ORCID: 0000-0001-8244-4163

Universiti Kebangsaan Malaysia Medical Centre, Hospital Canselor Tuanku Muhriz, Department of Pathology, Kuala Lumpur, Malaysia 


\section{INTRODUCTION}

Angiosarcoma is one of the rarest forms of malignant vascular tumours that arise from vascular endothelial cells, which accounts for about $1 \%$ of all sarcomas ${ }^{1}$. Fifty-two per cent of angiosarcomas occur in the head and neck region with a predilection of scalp and superficial soft tissue involvement ${ }^{2}$. Angiosarcoma arising from the deep cervical soft tissue is extremely rare $^{3}$. There is a limited literature on angiosarcoma with coexisting papillary thyroid carcinoma (PTC). A case of PTC with an unexpected diagnosis of concurrent angiosarcoma after thyroid surgery is presented and discussed here. Although thyroidectomy was performed successfully, the aggressive angiosarcoma succumbed the patient to death.

\section{CASE PRESENTATION}

A 66-year-old Malay female without known medical illnesses, presented with six months history of right neck swelling. It was painless and gradually increased in size. Otherwise, she had not any symptoms of obstruction, voice change, noisy breathing, or aspiration. There was no constitutional symptoms or symptoms suggestive of thyroid hormone dysfunction. Examination showed a non-tender, large lobulated mass at right level III and IV of the neck measuring $10 \times 8 \mathrm{~cm}$. The mass was firm at the medial surface but cystic and fixed to the underlying structures laterally. The overlying skin appeared normal and not tethered. The trachea was deviated to the left due to the pressure effect of the mass. Laryngeal crepitus was present. There was no hoarseness or sign of upper airway obstruction such as stridor. No cutaneous or scalp lesions was seen. Assessment by flexible endoscopy showed normal supraglottic and glottic structures. Both vocal cords were mobile symmetrically. Tracheoscopy under local anaesthesia revealed an irregular reddish mass at the right anterolateral aspect of the subglottis extending inferiorly to the first tracheal ring (Figure 1).
Fine needle aspiration cytology (FNAC) of the anterior neck swelling was reported as papillary thyroid carcinoma; whilst the right lateral neck swelling showed malignant cells. Ultrasonography of the neck revealed a large heterogeneous mass at the thyroid isthmus measuring $2.2 \times 3.2 \times 4.2$ $\mathrm{cm}$, continuous with a large predominantly cystic lesion at the right thyroid lobe measuring $4.2 \times 4.3 \times 4.4 \mathrm{~cm}$. Hyperechoic solid component

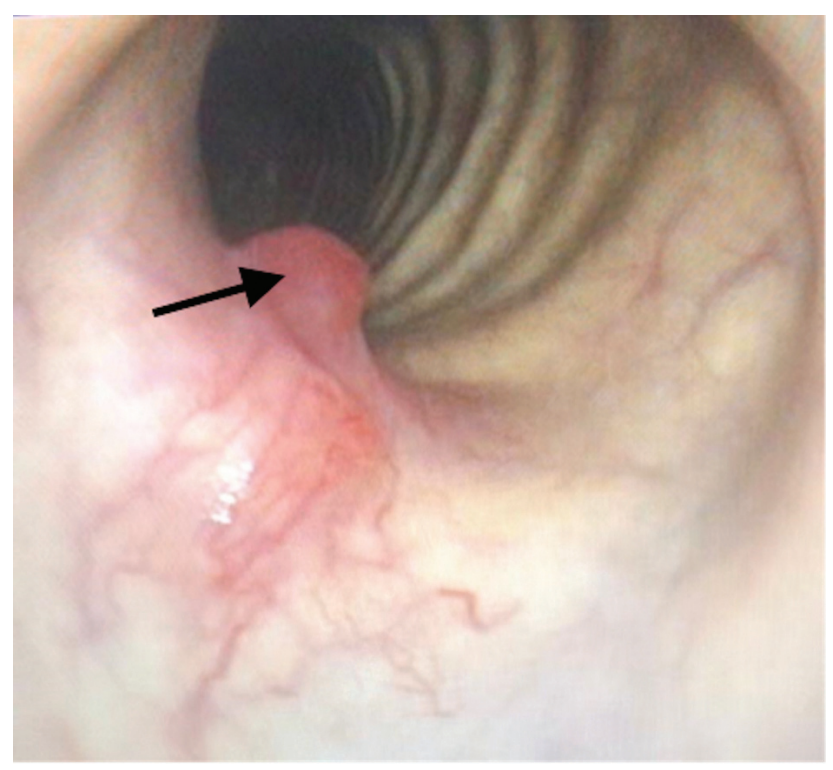

Figure 1. Endoscopic view showing a reddish (arrow) at the right anterolateral aspect of subglottis and first tracheal ring.

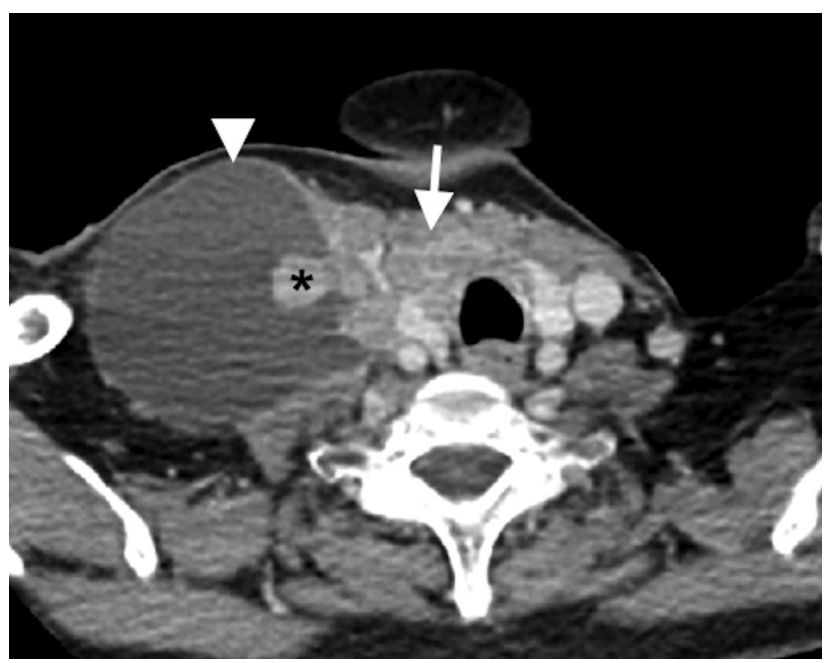

Figure 2. Axial CECT neck showing irregular enhancing thyroid mass (white arrow) and a large right cervical cystic mass (white arrowhead) with multiple enhancing mural nodules encasing the right IJV $\left({ }^{*}\right)$. 
with internal vascularity was seen in the large cystic lesion. These masses were encasing the right internal jugular vein (IJV). The right carotid artery was displaced medially but remained patent. There was no retrosternal extension. The mass was classified as TIRADS 5 that indicates high suspicion for malignancy.

Contrast-enhanced computed tomography (CECT) of the neck and thorax showed an ill-defined enhancing solid mass with a cystic component at the thyroid isthmus measuring $2.7 \times 3.4 \times 4.4 \mathrm{~cm}$ (Figure 2). The tumour had infiltrated the overlying strap muscles and right sternocleidomastoid muscle. It had also infiltrated the anterior tracheal

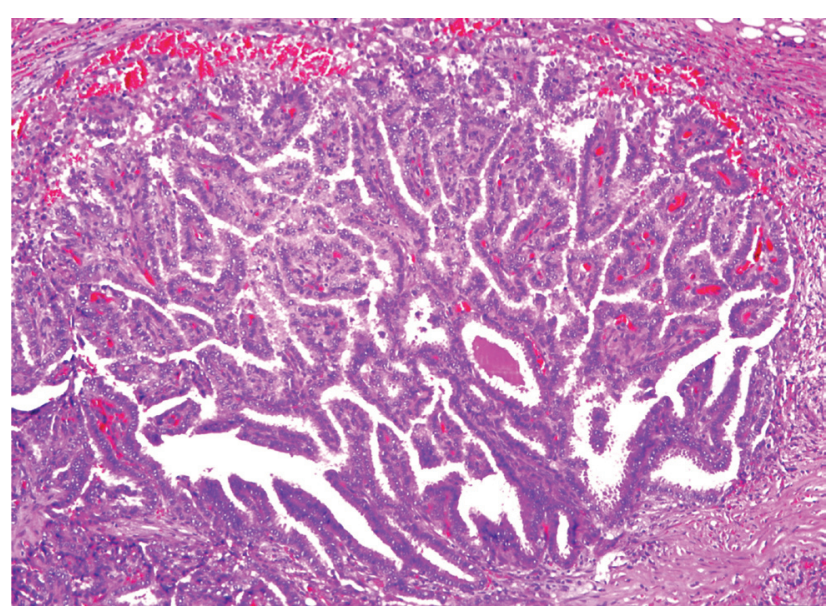

Figure 3a. The malignant thyroid cells arranged in a papillary pattern with central fibrovascular core (H\&E, X40).

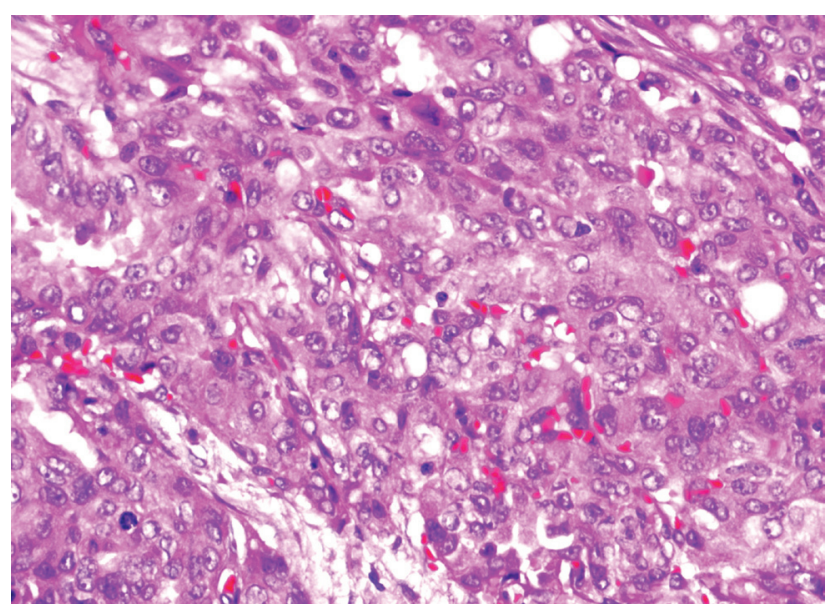

Figure 3b. The malignant thyroid cells display features of nuclear clearing, nuclear grooving and intranuclear inclusion (H\&E, X100). wall into the tracheal lumen at the level of the thyroid gland. Laterally the large cystic mass encased the right internal jugular vein (IJV) but it remained patent. Internal carotid arteries were not involved. There were multiple enlarged cervical lymph nodes seen at bilateral level II, right level IV, and VI with the largest at level IV measuring $6.2 \mathrm{~cm}$. The nodes showed a central necrotic component with multiple enhancing mural nodules.

She was diagnosed to have papillary thyroid carcinoma with cervical lymph node metastases and underwent open total thyroidectomy, bilateral neck dissection (Level II, III, IV, and VI lymphatic groups), and cricotracheal window resection un-

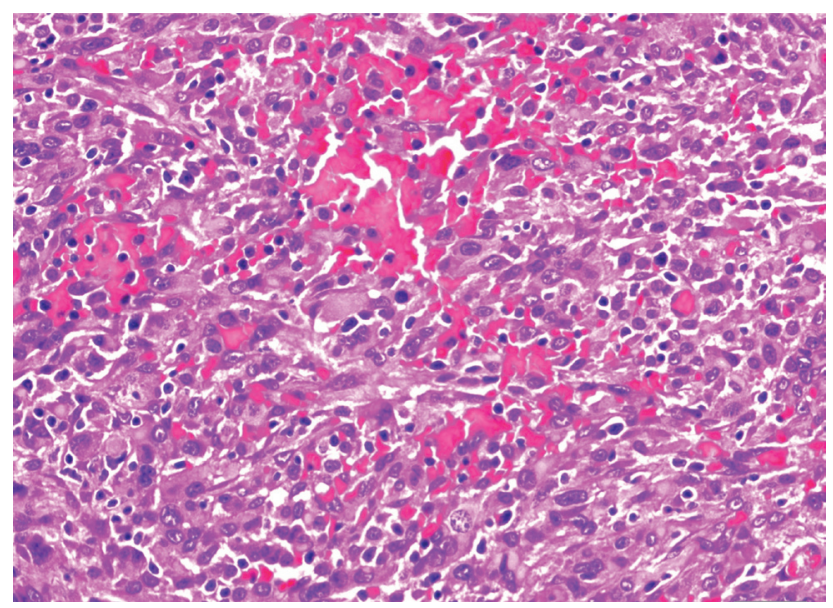

Figure 3c. The malignant cells of the right cervical cystic mass is lining small vascular spaces, have large pleomorphic nuclei with prominent eosinophilic macronucleoli and abundant eosinophilic cytoplasm (H\&E, X100).

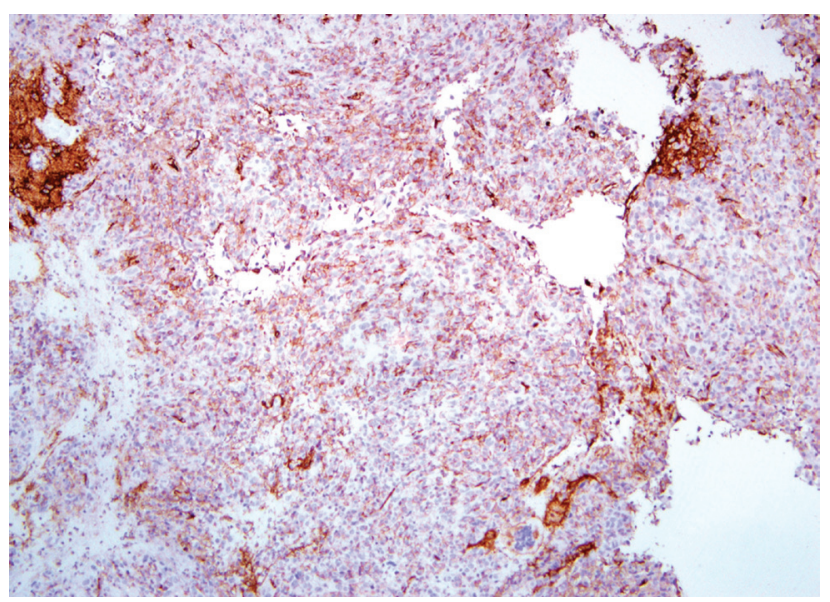

Figure 3d. IHC stain of the right cervical cystic mass showed CD31 positive. 
der general anaesthesia. The tumour was found to arise from the thyroid gland and had infiltrated the strap muscles. There were multiple enlarged lymph nodes at bilateral level II, III, IV, and VI. The largest mass was located at right level II to IV, which showed cystic and solid components. It was adherent and encasing the right IJV, unable to be separated apart. Therefore, the right IJV was ligated and excised together with the lymph nodes. It was noted that the tumour had eroded through the right anterolateral aspect of cricoid, first and second tracheal cartilages, with intraluminal extension. A tracheostomy tube was inserted following the window resection and partial anastomosis of the diseased trachea. She was nursed in the intensive care unit during the postoperative period, and an uneventful recovery was achieved. The tracheostomy tube was successfully decannulated one month later.

The histopathological report confirmed papillary thyroid carcinoma with tracheal and cricoid cartilage invasion, stage pT4a pN1b (AJCC 2017). There were 10/40 metastatic lymph nodes at right level II, III, IV and VI (Figure 3a, 3b). No lymphovascular invasion was identified, and the surgical margins over the cricotracheal resection area were negative for malignancy. However, a different pathology was reported for the cystic mass specimen originating from the right neck. These malignant cells demonstrated complete different cytopathological characteristics from the thyroid malignant cells (Figure 3c, 3d). On immunohistochemical (IHC) staining, the malignant cells were positive for CK and CD31, negative for CD68, TTF-1 and thyroglobulin. These features were consistent with epithelioid angiosarcoma.

She was referred to an oncologist for further treatment of the two simultaneous primary tumours. However, at the sixth postoperative week, she presented to the emergency department with progressive right neck swelling for two weeks duration. There was no fever, hoarseness, or aspiration symptoms. On examination, she was not in respiratory distress and there was no audible stridor. The neck swelling located underneath the previous surgical scar, appeared to have a rugged surface, measuring $9 \times 6 \mathrm{~cm}$ (Figure 4). It was firm, warm, and slightly tender on palpation. The overlying skin appeared tethered with reddishpurplish discolouration. Upper airway assessment by flexible endoscopy showed reduced mobility of the right vocal cord. A repeated CT of the neck

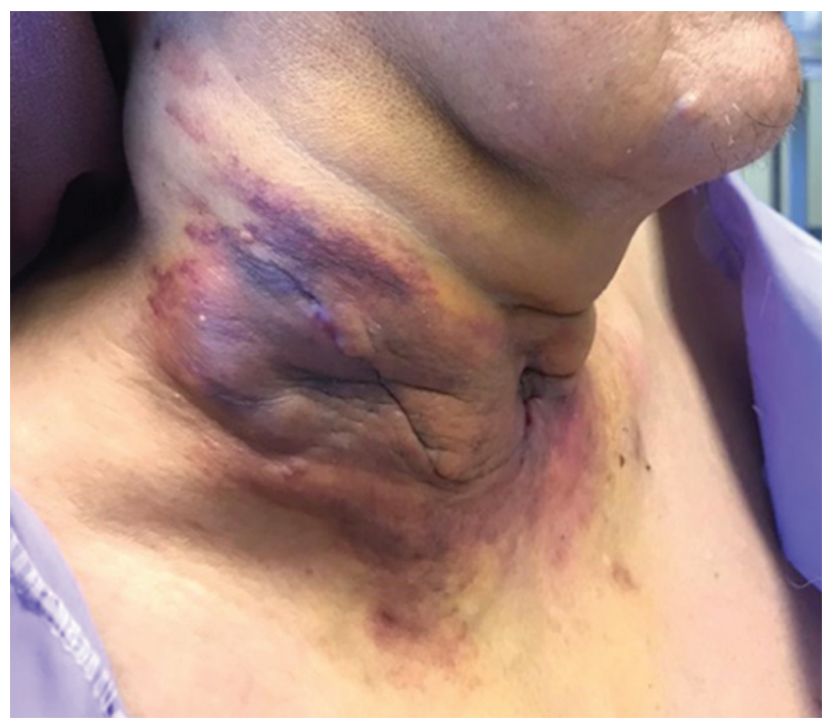

Figure 4. Right neck swelling underneath the previous surgical incision; the overlying skin appeared irregular with reddish-purplish discolouration.

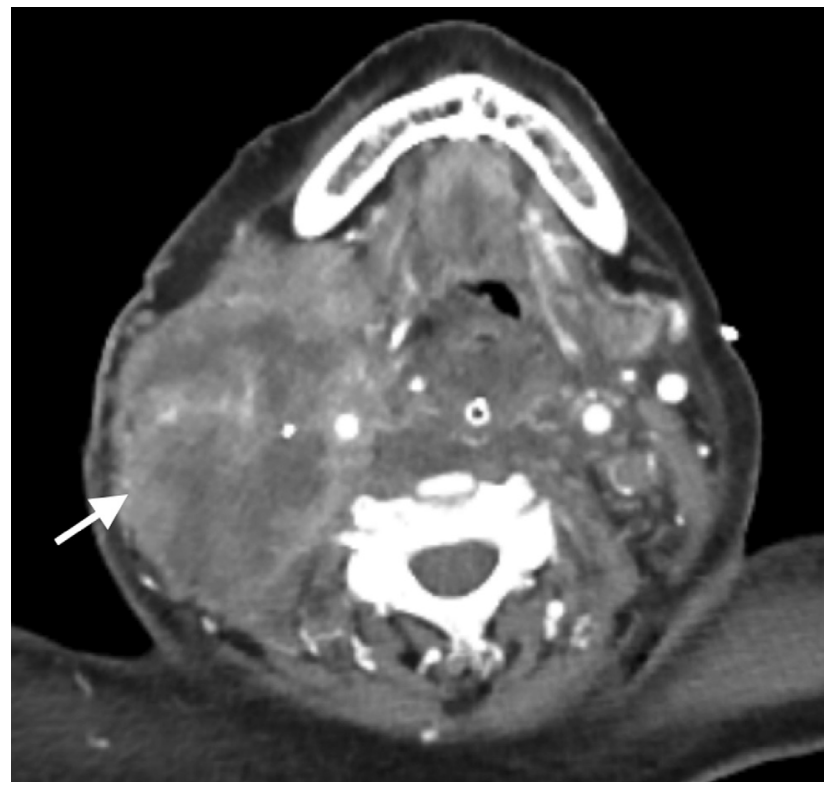

Figure 5. Axial CECT neck shows an ill-defined heterogeneous lesion. 
showed an ill-defined heterogeneous lesion with air pockets at the previous surgical bed measuring $6.1 \times 10.2 \times 14.5 \mathrm{~cm}$ with extension to the right lateral neck, retropharyngeal space, and superior mediastinum (Figure 5). Bilateral pleural effusion was worse on the right, and lung nodules was also seen. Based on the clinical features and CT findings, postoperative diagnosis of infected hematoma was made, with the possibility of progression to a malignant tumour.

The patient was treated with intravenous antibiotic and a right chest tube was inserted to drain the pleural effusion. She agreed for evacuation of the infected hematoma after multidisciplinary discussion and family conference. However, she developed respiratory failure due to pneumonia and worsening pleural effusion before the surgery. She underwent emergency tracheostomy, neck exploration, and evacuation of the hematoma. After blood clot was evacuated from the wound, there was a residual tumour with necrotic tissue at the previous surgical bed, which had also infiltrated the subcutaneous tissue. A repeat biopsy confirmed the presence of a residual epithelioid angiosarcoma. The malignant cells were positive for CKAE1/AE3 (diffuse), CD31 (focal), CD34 (very focal), and EMA (focal). She was nursed in ICU, but her condition further deteriorated with multiorgan failure, and eventually succumbed to the disease two weeks later.

\section{DISCUSSION}

Angiosarcoma is one of the rarest forms of malignant vascular tumours, also known as malignant hemangioendothelioma or hemangiosarcoma. It arises from vascular endothelial cells, and accounts for about $1 \%$ of all sarcomas ${ }^{4}$. The tumour can be classified into cutaneous, visceral, and soft tissue subtypes. Angiosarcoma have a variety of histological morphologies such as papillary, spindled, and epithelioid features. Epithelioid angiosarcoma has a unique morphology in which it has a predominant epithelioid appearance of the malig- nant endothelial cells. They are mostly soft tissue subtypes and commonly found in adult male, particularly in the seventh decade ${ }^{5}$. About $52 \%$ of all angiosarcomas involve the head and neck region, predominantly affecting the scalp and superficial soft tissues; angiosarcoma arising from the deep cervical soft tissue is extremely rare ${ }^{2,3}$.

The presentation of epithelioid angiosarcoma varies depending on the location of the affected areas. Based on a case series by Yang et al. ${ }^{2}$, head and neck angiosarcomas exhibited a wide spectrum of presentations including purple macular lesions that resembled bruises or hemangioma, edema or ulceration mimicking an infective process, growing mass with bleeding tendencies, hematoma, and satellite lesions.

Angiosarcoma has a variety of histological characteristics. Among all, three main histological features are sheets of cells, rudimentary vascular channels, and undifferentiated cell morphology. An anastomosing network formed by vascular channel lined by neoplastic endothelium connecting each other with the sheets of rounded epithelioid cells ${ }^{3}$. Immunohistochemical staining has paramount importance in making the diagnosis. Fifty per cent of angiosarcomas have a positive CD34 expression. This staining feature, however, is nonspecific as it can be positive in Kaposi sarcoma and other soft tissue sarcomas as well. Another marker namely CD31 is more sensitive and specific for endothelial differentiation in which 80-90\% of angiosarcomas express this antigen. Therefore, It is deemed to be the most reliable marker in the diagnosis of angiosarcoma ${ }^{2,3}$. These findings correlate well with this case as the cystic mass specimen demonstrated positivity for CD31 and very focal positivity for CD34.

Soft tissue angiosarcoma disseminates via haematogenous route and has a high risk of local recurrences. It mostly affects the lungs, followed by lymph nodes, soft tissue, and bone. It is often related to poor prognosis, with a five-year survival 
rate of $10-35 \%$, five-year local-regional control rate of $40-50 \%$ and five-year distant metastasisfree survival rate of $20-40 \%^{2}$. Poor prognostic factors are old age, tumour size more than $5 \mathrm{~cm}$, high grade, positive surgical margin, and lymphoedema field location ${ }^{4}$.

Due to the rarity of angiosarcoma, optimal treatment has not been established. However, surgical resection with adequate margins and then postoperative radiotherapy was reported to be the treatment of choice in treating soft tissue angiosarcoma ${ }^{6}$. Cytotoxic chemotherapy was shown to have a little role in improving overall survival and local control. The recent discovery for the role of the molecular-targeted immunotherapy with bevacizumab, pazopanib, sorafenib or sunitinib has shown to be effective in treating angiosarcoma ${ }^{3,7}$.

In this case, many peculiar points that steered the clinicians away from making the diagnosis of angiosarcoma. Firstly, this patient had no scalp or skin lesion, and no prior significant history to suggest angiosarcoma as one of the differential diagnosis. The initial working diagnosis after FNAC was papillary thyroid carcinoma with cervical lymph node metastases, and local subglottic and intratracheal invasion. In the initial CT scan, there was no obvious lesion seen elsewhere in the body besides in the neck and the lungs. In addition, the angiosarcoma in this patient was presented as a huge cystic mass unlike most of the reported cases in the literature, which indicated that patients usually presented with bleeding tendencies and compressive symptoms.

In the present case, there are a few possibilities for the origin of angiosarcoma. It can either arise from the IJV, deep cervical soft tissues, or transformation of the concomitant papillary thyroid carcinoma. There is a scarce literature available describing the probabilities of each condition. This has posed a challenge to the clinician in diagnosis and constructing a treatment strategy for this patient. Yu et al. ${ }^{6}$ reported a fairly similar case, in which the patient had coexistence of high-grade angiosarcoma of the neck with follicular variant papillary thyroid carcinoma. They concluded that the angiosarcoma arised from the lower neck soft tissues and invaded directly into the thyroid gland. However, it is difficult to ascertain the precise site of the origin of angiosarcoma due to extensive involvement of the surrounding structures. The findings in this case where the cystic mass encased and invaded the IJV may indicate that the angiosarcoma in fact arises from the wall of the vessel. Several other authors had described the simultaneous occurrence of papillary thyroid carcinoma with thyroid angiosarcoma. However, they postulated that the presence of an isolated microscopic focus of papillary thyroid carcinoma in their patients was likely to be coincidental. Further clarification is important in proving the hypothesis that malignant neoplasms may exhibit dual differentiation ${ }^{8,9}$.

In this case, another postulation is the possibility of the presence of an extrathyroidal angiosarcoma that gives rise to thyroid metastases. This can be excluded by performing whole-body imaging to look for the possible primary location of the angiosarcoma as there is no histological features that can differentiate the primary one from metastatic lesions ${ }^{9}$. Anaplastic transformation with angiomatoid features from a pre-existing differentiated thyroid carcinoma could be another probability, as PTC is the most common type associated with anaplastic transformation ${ }^{10}$. However, the transformation process may take about five to 20 years to develop, and as a matter of fact, IHC stains of TTF-1 and thyroglobulin were negative in this case. In addition, pathologists previously believed that thyroid angiosarcoma was actually an anaplastic thyroid carcinoma with angiomatoid features. However, it has been proven to be inaccurate with the current widespread practice of confirmatory IHC staining using CD31 for epithelioid angiosarcoma, which is negative in anaplastic thyroid carcinoma? 


\section{CONCLUSION}

This paper presented and discussed a rare case of simultaneous double primary tumours of PTC coexisting with deep cervical epithelioid angiosarcoma. Their rarity and proximity to each other made the diagnosis extremely difficult. Besides, the rapid progression of the residual angiosarcoma that resembled postoperative hematoma was another major diagnostic challenge. Due to the distinct difference in terms of nature and malignant behaviour, a comprehensive treatment strategy to address both concurrent primary tumours is essential to improve the patient outcome.

\section{REFERENCES}

1. Koch M, Nielsen GP, Yoon SS. Malignant tumors of blood vessels: Angiosarcomas, hemangioendotheliomas, and hemangioperictyomas. J Surg Oncol. 2008;97:321-9. [CrossRef]

2. Yang XJ, Zheng JW, Zhou Q, et al. Angiosarcomas of the head and neck: a clinico-immunohistochemical study of 8 consecutive patients. Int J Oral Maxillofac Surg. 2010;39:568-72. [CrossRef]

3. Kishimoto I, Kikuchi M, Shinohara S, R et al. A case of angiosarcoma arising from internal jugular vein. Auris Nasus Larynx. 2015;42:68-71. [CrossRef]

4. Wu J, Li X, Liu X. Epithelioid angiosarcoma: a clinicopathological study of 16 Chinese cases. Int J Clin Exp Pathol. 2015;8:3901-9.

5. Hart J, Mandavilli S. Epithelioid Angiosarcoma: A Brief Diagnostic Review and Differential Diagnosis. Arch Pathol Lab Med. 2011;135:268-72.

6. Yu J, Steiner FA, Muench JP, et al. Juxtathyroidal Neck Soft Tissue Angiosarcoma Presenting as an Undifferentiated Thyroid Carcinoma. Thyroid. 2002;12:427-32. [CrossRef]

7. Kaur A, Didolkar MS, Thomas A. Angiosarcoma of the Thyroid: a Case Report with Review of the Literature. Endocr Pathol. 2013;24:156-61. [CrossRef]

8. Kefeli M, Mete O. An Unusual Malignant Thyroid Nodule: Coexistence of Epithelioid Angiosarcoma and Follicular Variant Papillary Thyroid Carcinoma. Endocr Pathol. 2014;25:350-2. [CrossRef]

9. Crawford MR, Berber E, Arrossi AV, Dobri G. Epithelioid Angiosarcoma of The Thyroid Associated With Multinodular Goiter, Graves Disease, And Papillary Thyroid Carcinoma. AACE Clin Case Rep. 2017;3:e374-8. [CrossRef]

10. Abe T, Suzuki M, Shimizu K, et al. Anaplastic transformation of papillary thyroid carcinoma in multiple lung metastases presenting with a malignant pleural effusion: a case report. J Med Case Reports. 2014;8:460. [CrossRef] 